\title{
Examining relations between interpersonal flexibility, self-esteem, and death anxiety
}

\author{
HOLLY R. MILLER, STEPHEN F. DAVIS, and KAIRA M. HAYES \\ Emporia State University, Emporia, Kansas
}

\begin{abstract}
The relations between interpersonal flexibility, level of self-esteem, and death anxiety in college students were examined. The results indicated that interpersonal flexibility and self-esteem were positively related, but that interpersonal flexibility and death anxiety were not related to each other in a reliable manner. A significant negative relation was found between self-esteem and death anxiety.
\end{abstract}

Interpersonal flexibility describes the process by which an individual changes behavior according to situational demands that are interpersonal in nature. In other words, one has the capability to adapt one's behavior to meet the interpersonal goals of the moment (Paulhus \& Martin, 1987, 1988). This concept can be likened to selfmonitoring - acting either consistently or inconsistently with one's internal traits. A high self-monitoring individual would be expected to possess a high degree of interpersonal flexibility. Conversely, a low self-monitoring individual would be expected to possess a low degree of interpersonal flexibility.

The Battery of Interpersonal Capabilities (BIC; Paulhus \& Martin, 1987) was developed to measure one's interpersonal capability; it has been linked to job success and business situations. Recent data reported by Hayes and Davis (1993) indicated that while interpersonal flexibility was not related to Type A characteristics, it was negatively related to imposter characteristics.

In the present study, we sought to extend the range of applicability of the BIC by evaluating the relations of two additional personality variables, level of self-esteem and death anxiety, with interpersonal flexibility. Because anxiety can be detrimental to interpersonal adaptation, it was hypothesized that death anxiety and interpersonal flexibility would be negatively related. Conversely, high levels of self-esteem should promote increased adaptability (interpersonal flexibility). Hence, the relation between selfesteem and interpersonal flexibility should be positive.

\section{METHOD}

\section{Subjects}

Sixty-four undergraduate students (35 women, 29 men) enrolled at a midwestern state university volunteered to serve as subjects. The mean age for the female subjects was $\mathbf{2 0 . 3 6}$ years; that for the male subjects was 19.59 years.

Correspondence should be addressed to S. F. Davis, Department of Psychology, Emporia State University, KS 66801-5087.

\section{Testing Instruments}

The BIC, Texas Social Behavior Inventory (TSBI; Helmreich \& Stapp, 1974), and Death Anxiety Scale (DAS; Templer, 1970) were used to measure interpersonal flexibility, self-esteem, and death anxiety, respectively. The testing instruments and a demographic sheet requesting gender, age, classification, and major were combined to form a selfadministered questionnaire booklet.

The BIC is a self-report inventory that asks the respondents five questions relating to their perceived capability to exhibit each of 16 different personality traits. Each question is evaluated on a 7-point Likert-type scale $(1=$ not at all; $7=$ very $)$.

The DAS consists of 15 true-false questions and has a test-retest reliability of .83 (Templer, 1970). It has been shown that the DAS correlates significantly with Boyar's Fear of Death Scale and the Welsh Anxiety Scale on the MMPI (Templer, 1970).

Form A of the TSBI was employed to evaluate level of self-esteem. The TSBI is a 16-item scale designed to provide "an objective measure of self-esteem or social competence”' (Helmreich \& Stapp, 1974, p. 473).

\section{Procedure}

An informed consent form and the questionnaire booklets were completed during a regular class session. No time limit was imposed, but all subjects completed the booklets within $20 \mathrm{~min}$. In order to ensure anonymity, the booklets and informed consent forms were collected separately.

\section{RESULTS AND DISCUSSION}

Pearson product moment correlation coefficients among scores on the BIC, TSBI, and DAS were calculated for the samples of men and women. The correlations for the men and women are shown in Tables 1 and 2, respectively. Two-tailed tests of significance and an alpha level of .05 were employed in all tests of significance.

Differences in self-esteem, interpersonal flexibility, and death anxiety between men and women were also analyzed. The results of these analyses indicated that men and women did not differ in terms of interpersonal flexibility $[t(63)=.03, p>.96]$ or self-esteem $[t(63)=.22$, $p>$.80]. However, the women had significantly higher scores on the death anxiety scale than did the men $[t(63)=$ $3.46, p<.01]$.

The significant correlations between the TSBI and BIC indicate that higher self-esteem scores were associated with higher interpersonal flexibility scores and supports 
Table 1

Correlation Coeficients for Interpersonal Flexibility (BIC), Self-Esteem (TSBI), and Death Anxiety (DAS)-Men

\begin{tabular}{lccc}
\hline & BIC & TSBI & DAS \\
\hline BIC & - & $.36^{*}$ & -.09 \\
TSBI & & - & $-.47 \dagger$ \\
DAS & & & - \\
\hline
\end{tabular}

${ }^{*} p<.02 . \quad+p<.01$.

Table 2

Correlation Coefficients for Interpersonal Flexibility (BIC), Self-Esteem (TSBI), and Death Anxiety (DAS)-Women

\begin{tabular}{cccc}
\hline & BIC & TSBI & DAS \\
\hline BIC & - & $.30^{*}$ & -.02 \\
TSBI & & - & $-.45 \dagger$ \\
DAS & & & - \\
\hline${ }^{*} p<.05 . \quad+p<.02$. & &
\end{tabular}

our initial prediction. The finding that self-esteem and death anxiety are negatively correlated also supports the prediction that higher levels of anxiety would be paired with lower interpersonal abilities. However, the lack of a relation between interpersonal flexibility and death anxiety was surprising and suggests that further research on this clustering of factors is needed.

The present data also replicate two previous findings: (1) the negative relationship between self-esteem and death anxiety (Buzzanga, Miller, Perne, Sander, \& Davis, 1989; Davis, Martin, Wilee, \& Voorhees, 1978), and (2) the display of higher levels of death anxiety by women than by men (Koob \& Davis, 1977; Sadowski, Davis, Loftus-Vergari, 1979; Tramill, Kleinhammer-Tramill, Davis, Parks, \& Alexander, 1984). The finding that men and women did not differ on level of self-esteem contradicts earlier reports (Davis et al., 1978), but corroborates more recent data (Buzzanga et al., 1989). Thus, it appears that a previously reported gender difference may be dissipating.

\section{REFERENCES}

Buzzanga, V. L., Miller, H. R., Perne, S. E., Sander, J. A., \& DAvis, S. F. (1989). The relationship between death anxiety and level of self-esteem: A reassessment. Bulletin of the Psychonomic Society, 27, 570-572.

Davis, S. F., Martin, D. A., Wilee, C. T., \& Voorhees, J. W. (1978). Relationship between fear of death and level of self-esteem in college students. Psychological Reports, 42, 419-422.

Hayes, K. M., \& Davis, S. F. (1993). Interpersonal flexibility, Type A individuals, and the imposter phenomenon. Bulletin of the Psychonomic Society, 31, 323-325.

Helmreich, R., StaPP, J. (1974). Short forms of the Texas Social Behavior Inventory (TSBI), an objective measure of self-esteem. Bulletin of the Psychonomic Society, 4, 473-475.

Коов, P. B., DAvis, S. F. (1977). Fear of death in military officers and their wives. Psychological Reports, 40, 261-262.

Paulhus, D. L., \& Martin, C. L. (1987). The structure of personal capabilities. Journal of Personality \& Social Psychology, 52, 354-365.

Paulhus, D. L., \& Martin, C. L. (1988). Functional flexibility: A new conception of interpersonal flexibility. Journal of Personality \& Social Psychology, 55, 88-101.

Sadowski, C. J., Davis, S. F., \& Loftus-Vergari, M. C. (1979). Locus of control and death anxiety: A reexamination. Omega, 10, 203-209.

Templer, D. I. (1970). The construction and validation of a death anxiety scale. Journal of General Psychology, 82, 165-177.

Tramill, J. L., Kleinhammer-Tramill, P. J., Davis, S. F., Parks, C. S., \& AleXANDER, D. (1984). The relationship between the Type A behavior pattern, fear of death, and manifest anxiety. Bulletin of the Psychonomic Society, 22, 42-44.

(Manuscript received May 17, 1993.) 